\title{
Preliminary use of a double-flanged, fully covered, self-expandable, metal stent with cautery in endoscopic ultrasound-guided gastroenterostomy
}

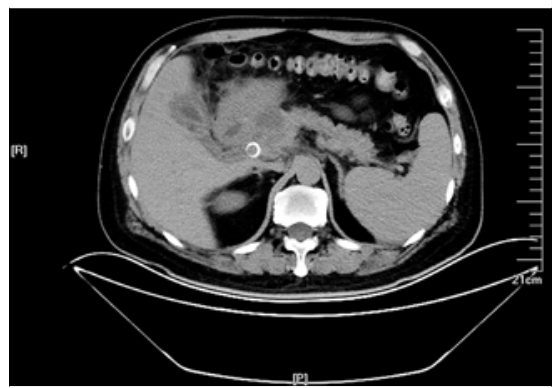

Fig. 1 Computed tomography scan showing edematous walls of the gastrointestinal tract, a large cystic mass with solid component (in the pancreatic head), and a fully covered metal stent that had been previously placed in the common bile duct.

New approaches to endoscopic ultrasound-guided gastroenterostomy (EUSGE) are under development, incorporating devices designed for transluminal therapy. Herein is the initial reported use of a novel, double-flanged, fully covered, self-expandable, metal stent with cautery, aimed at refining the EUS-GE procedure.

A 43-year-old man was diagnosed with paraduodenal pancreatitis and walledoff necrosis (WON) due to biliary pancreatitis. He showed symptoms of gastric outlet obstruction (GOO), such as vomiting. Computed tomography (CT) images revealed a large cystic mass occupying the pancreatic head and a fully covered metal stent in the common bile duct, which was deployed previously for biliary pancreatitis ( Fig. 1).

Treatment was aimed at drainage of the infected WON and relief from the symptoms of GOO. EUS-guided drainage of the WON was achieved using a fully covered, double-flanged, metal stent as previously reported [1,2]. After 15 days, the patient's condition had stabilized sufficiently for EUS-GE to be performed ( $\vee$ Video 1)

The patient was placed in the prone position for the procedure and given general

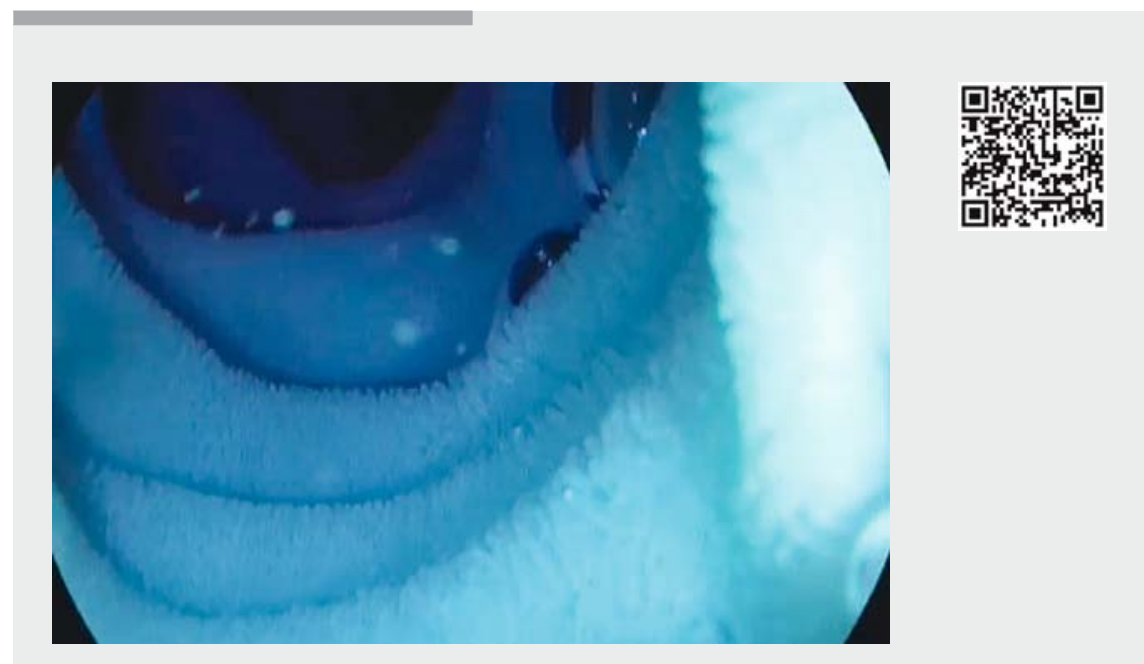

Video 1 Endoscopic ultrasound-guided gastroenterostomy with novel, double-flanged, fully covered, self-expandable, metal stent with cautery.
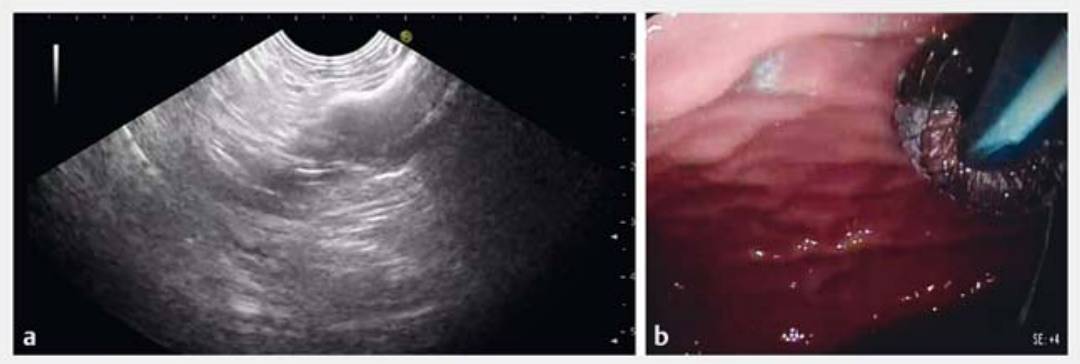

Fig. 2 Deploying the stent. a Endoscopic ultrasound view. b Endoscopic view.

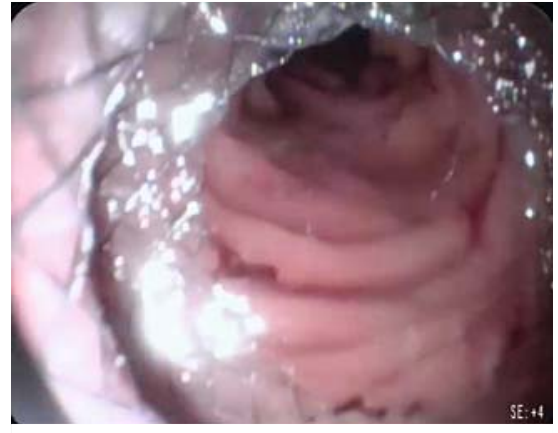

- Fig. 3 Successful deployment of the stent was confirmed by endoscopic visibility of the small bowel through the stent lumen.

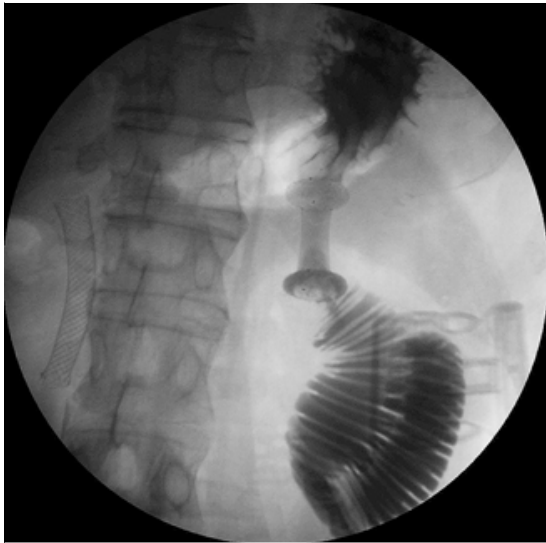

Fig. 4 Fluoroscopic image showing patent and properly positioned stent. 
anesthesia. Initially, a gastroscope was advanced into the horizontal part of the duodenum across the stenotic segment, and methylene blue-tinted saline was instilled $(\sim 800 \mathrm{~mL})$. The gastroscope was subsequently withdrawn and replaced with a longitudinal echoendoscope, which was stationed at the posterior wall of the gastric body. EUS imaging of the dilated bowel adjacent to the stomach was obtained, and a 19-gauge fine-needle aspiration needle was used to puncture the site under EUS guidance. After confirming the correct location (in the jejunum) by return of blue-colored saline, a guidewire was inserted through the needle bore. The novel stent was introduced under endosonographic and fluoroscopic visualization, with cautery-aided catheter passage (via the guidewire) into the lumen of the small bowel. The distal stent flange was then deployed under EUS guidance, and the proximal flange was deployed under direct endoscopic visualization (\$Fig.2). Finally, a $12 \mathrm{~mm}$ dilation balloon was used to expand the stent lumen, allowing easy endoscope advancement into the bowel (> Fig.3). Stent patency and intended position were verified by fluoroscopic inspection ( Fig.4). At completion of EUS-GE, the metal stent placed for WON drainage was snared for removal, and necrosectomy was performed using a stone basket.

Postoperatively, the patient began a liquid diet on postoperative Day 2, without adverse consequences (i.e. bleeding, infection, or abdominal pain). Gastric emptying, checked 7 days after stent placement, indicated a patent anastomosis and normal gastric function. The patient was discharged from the hospital 8 days postoperatively, with planned stent removal in 1-2 months, if permissible by endoscopic and fluoroscopic outcomes. In the treatment of GOO, customary surgical treatment (i.e. gastrojejunostomy) is associated with morbidity and mortality [3]. EUS-GE has become a viable alternative to endoscopic enteral stenting and surgical gastroenterostomy. Other reported case series have differed in approach, using such means as direct or balloon-assisted EUS-GE and EUS-guided balloon-occluded gastrojejunostomy bypass (EPASS) $[4,5]$.

These currently used techniques have been detailed in previous publications, but the chief differences from our method are as follows. 1) Direct EUS-GE: after infusion of fluids, the small bowel is punctured using an aspiration biopsy needle or pierced directly by the cautery tip of a lumen-apposing metal stent. 2) Balloonassisted EUS-GE: a retrieval or dilating balloon catheter is passed, with 19 gauge needle puncture. 3) EPASS: a specially designed double-balloon enteric tube (capable of holding contrast material) is placed between two balloons in the small bowel.

These techniques all necessitate tract dilation before stent placement or the implementation of other devices. However, by combining features used elsewhere, we have effectively coupled a doubleflanged, fully covered, self-expandable metal stent (length $3.5 \mathrm{~cm}$, width $2.5 \mathrm{~cm}$, diameter $1.6 \mathrm{~cm}$ ) with a cautery probe, enabling direct small-bowel puncture and stent deployment in contiguity. Leakage due to overly aggressive dilation is avoided and, thus, the risk of adverse events is minimized. Our device reduces the need for accessory exchanges and lessens the impact on patients.

From our perspective, the treatment of paraduodenal pancreatitis seems controversial, with no real consensus at present [6]. The approach described here constitutes a new and promising therapeutic option as an alternative to existing medical or surgical interventions. A device of this nature simplifies and refines the EUS-GE procedure, tem- porarily restoring enteric transit, and benefitting patients. In principle, its merit may well extend to drainage of pancreatic fluid collections or gallbladder contents.

Endoscopy_UCTN_Code_TTT_1AS_2AG

Competing interests

None

The authors

Bowen Duan, Jintao Guo, Nan Ge, Xiang Liu, Sheng Wang, Guoxin Wang, Siyu Sun Endoscopy Center, Shengjing Hospital of China Medical University, Shenyang, China

Corresponding author

Siyu Sun, MD

Endoscopy Center, Shengjing Hospital of China Medical University, 36 Sanhao Street, Shenyang, Liaoning Province, China, 110004 Fax: +86-24-23892617

sun-siyu@163.com

\section{References}

[1] Ang TL, Kongkam P, Kwek AB et al. A twocenter comparative study of plastic and lumen-apposing large diameter self-expandable metallic stents in endoscopic ultrasound-guided drainage of pancreatic fluid collections. Endosc Ultrasound 2016; 5: 320-327

[2] Adler DG, Siddiqui AA. What's in a name? Pancreatic pseudocysts, walled-off necrosis, and pancreatic fluid collections. Endosc Ultrasound 2016; 5: 215-217

[3] Maetani I, Tada T, Ukita T et al. Comparison of duodenal stent placement with surgical gastrojejunostomy for palliation in patients with duodenal obstructions caused by pancreaticobiliary malignancies. Endoscopy 2004; 36: $73-78$ 
[4] Itoi T, Baron TH, Khashab MA et al. Technical review of endoscopic ultrasonographyguided gastroenterostomy in 2017. Dig Endosc 2017; 29: 495- 502

[5] Khashab MA, Bukhari M, Baron TH et al. International multicenter comparative trial of endoscopic ultrasonography-guided gastroenterostomy versus surgical gastrojejunostomy for the treatment of malignant gastric outlet obstruction. Endosc Int Open 2017; 5: E275-E281

[6] Campos LP, Mateu CA, Garcia-Arguelles JS et al. Cystic dystrophy of the duodenal wall: a rare but need-to-know disease. Endosc Ultrasound 2017; 6: 61-66

\section{Bibliography}

DOI https://doi.org/10.1055/s-0043-121135

Published online: 10.11.2017

Endoscopy 2018; 50: E29-E31

(c) Georg Thieme Verlag KG

Stuttgart · New York

ISSN 0013-726X

\section{ENDOSCOPY E-VIDEOS}

https:/|eref.thieme.de/e-videos

口回 Endoscopy E-Videos is a free 登视 靣程: on interesting cases and new

techniques in gastroenterological endoscopy. All papers include a high quality video and all contributions are freely accessible online.

This section has its own submission website at

https://mc.manuscriptcentral.com/e-videos 